\title{
Long non-coding RNA snaR is involved in the metastasis of liver cancer possibly through TGF-ß1
}

\author{
ZHITIAN SHI $^{1}$, DONG WEI ${ }^{1}$, HUAMEI WU $^{2}$, JIAYUN GE $^{1}$, XUEFEN LEI $^{3}$, ZHITANG GUO $^{1}$, RENCHAO ZOU $^{1}$, \\ SHUFENG XIAO ${ }^{1}$, TIANGEN WU ${ }^{1}$, RUICHENG MA ${ }^{1}$, RUNYAO AI ${ }^{1}$ and LIN WANG ${ }^{1}$ \\ Departments of ${ }^{1}$ Hepatopancreatobiliary Surgery, ${ }^{2}$ Digestive System and ${ }^{3}$ Oncology, \\ The Second Affiliated Hospital of Kunming Medical University, Kunming, Yunnan 650101, P.R. China
}

Received August 7, 2018; Accepted February 15, 2019

DOI: $10.3892 / 01.2019 .10258$

\begin{abstract}
It was previously demonstrated that the long non-coding RNA (lncRNA) small NF90-associated RNA (snaR) served an oncogenic role in human colon cancer, although its roles in other types of cancer remain unknown. To investigate the potential involvement of IncRNA snaR in hepatocellular carcinoma (HCC), expression of snaR in liver biopsies and plasma of patients with HCC and healthy controls was detected by reverse transcription-quantitative polymerase chain reaction. ELISA was used to determine the protein expression levels of transforming growth factor- $\beta 1$ (TGF- $\beta 1$ ). A snaR expression vector was transfected into HCC cells, and the effects on cell migration and invasion were analyzed by Transwell migration and Matrigel invasion assays, respectively. The protein expression levels of TGF- $\beta 1$ in HCC cells were detected by western blotting. The expression of snaR and TGF- $\beta 1$ was significantly increased in the patients with HCC compared with the healthy controls. The plasma expression levels of snaR and TGF- $\beta 1$ were positively correlated in patients with HCC; however, not in healthy controls. snaR overexpression significantly promoted cancer cell migration and invasion, and additionally increased TGF- $\beta 1$ expression. Treatment with TGF- $\beta 1$ did not significantly affect snaR expression. A TGF- $\beta 1$ inhibitor attenuated the effects of snaR overexpression in cancer cell migration and invasion. snaR may promote the metastasis of liver cancer through TGF- $\beta 1$.
\end{abstract}

\section{Introduction}

The treatment outcomes of non-metastatic tumors are frequently satisfactory (1); however, if the tumor cells become

Correspondence to: Dr Lin Wang, Department of Hepatopancreatobiliary Surgery, The Second Affiliated Hospital of Kunming Medical University, 374 Dianmian Road, Kunming, Yunnan 650101, P.R. China

E-mail: piwrqb5@163.com

Key words: liver cancer, long non-coding RNA small NF90-associated RNA, transforming growth factor- $\beta 1$, migration, invasion metastatic, the survival rate for patients with cancer is significantly decreased (2). Therefore, preventing and inhibiting the metastasis of cancer is a principal challenge in clinical practices. Liver cancer is the second most frequently diagnosed malignancy. Hepatocellular carcinoma (HCC) is the most commonly diagnosed liver cancer, which primarily affects middle-aged and older adults resulting in $>700,000$ mortalities every year (3). Chronic viral hepatitis infection is the principal cause of HCC worldwide (4). With an increase in the rate of viral hepatitis infections, the incidence of HCC is predicted to increase in certain regions, including China (5). Therefore, effective treatment strategies are required to improve the survival of patients with HCC.

Transforming growth factor- $\beta 1$ (TGF- $\beta 1$ ) signaling is a central pathway involved in the metastasis of different tumors (6). Activation of TGF- $\beta 1$ signaling mediates epithelial-mesenchymal transition (EMT), which facilitates metastasis (7). Inhibition of the signaling pathways initiated by TGF- $\beta 1$ has been considered as a potential approach for cancer treatment (8). Components of the TGF- $\beta 1$ signaling pathways interact with various signaling molecules, including different long non-coding RNAs (IncRNAs) $(9,10)$, which are a group of non-coding RNAs that are involved in physiological and pathological processes (11). Accumulating evidence has demonstrated the importance of lncRNAs in understanding cancer biology (12). lncRNA small NF90-associated RNA (snaR) is a previously identified lncRNA, which exhibited tumor suppression activity in human colon cancer (13), whereas, its involvement in other diseases is unknown. In the present study, snaR was upregulated in HCC and may be involved in the regulation of HCC metastasis through interactions with TGF- $\beta 1$ signaling.

\section{Patients and methods}

Participants. A total of 233 patients with HCC were treated at The Second Affiliated Hospital of Kunming Medical University (Kunming, China) between January 2015 and January 2018. From the 233 patients, 56 patients were enrolled based on strict inclusion and exclusion criteria. The inclusion criteria were: i) Patients who were diagnosed and treated for the first time at The Second Affiliated Hospital of Kunming Medical University; ii) patients who fully understood the experimental procedure; iii) patients younger than 70 years old; and iv) patients diagnosed 
by liver biopsy. The exclusion criteria were: i) Patients with other malignancies; ii) patients with other liver diseases and chronic diseases; and iii) patients who were treated prior to their admission at The Second Affiliated Hospital of Kunming Medical University. The final cohort of patients included 32 males and 24 females, age range between 30 and 68 years with an average age of $49.2 \pm 6.4$ years. Liver biopsies and plasma of those patients were collected. During the same period, a total of 102 individuals with suspected liver lesions were subjected to liver biopsy and liver lesions were not present in 46 of these cases. Amongst those 46 cases, 30 were included in the control group, of which 17 were male and 13 female. The average age was $50.4 \pm 6.9$ years (range, 32-69 years). These control patients were selected to match the age and sex distribution of the patients. Cases with a previous history of malignancies were excluded. Liver biopsies and plasma were additionally collected from the control group. Approval was obtained from the Ethics Committee of The Second Affiliated Hospital of Kunming Medical University and all patients signed informed consent.

Reverse transcription-quantitative polymerase chain reaction $(R T-q P C R)$. Total RNA was extracted from biopsies, plasma and cells using TRIzol ${ }^{\circledR}$ reagent (Invitrogen; Thermo Fisher Scientific, Inc., Waltham, MA, USA). RT was performed using SuperScript III Reverse Transcriptase kit (Thermo Fisher Scientific, Inc.) to synthesize cDNA at following temperature conditions: $25^{\circ} \mathrm{C}$ for $5 \mathrm{~min}, 55^{\circ} \mathrm{C}$ for $15 \mathrm{~min}$ and $80^{\circ} \mathrm{C}$ for 10 min. SYBR-Green Real-Time PCR Master Mixes (Thermo Fisher Scientific, Inc.) was used to prepare all PCR reactions. The PCR reaction conditions were $95^{\circ} \mathrm{C}$ for $1 \mathrm{~min}$, followed by 40 cycles of $95^{\circ} \mathrm{C}$ for $10 \mathrm{sec}$ and $60^{\circ} \mathrm{C}$ for $40 \mathrm{sec}$. Primers used in the PCR reactions were: snaR forward, 5'-TGGAGCCAT TGTGGCTCCGGCC-3' and reverse, 5'-CCCATGTGGACC AGGTTGGCCT-3'; and GAPDH forward, 5'-CAGGAGGCA TTGCTGATGAT-3' and reverse, 5'-GAAGGCTGGGGCTCA TTT-3.' The data were analyzed using the $2^{-\Delta \Delta \mathrm{Cq}}$ method (14).

Cell lines and cell transfection. HEP G2 and C33A were provided by American Type Culture Collection (ATCC; Manassas, VA, USA). Cells were cultured with RPMI-1640 medium (ATCC) containing 10\% fetal bovine serum (FBS; ATCC) at $37^{\circ} \mathrm{C}$ in an incubator with atmosphere of $5 \% \mathrm{CO}_{2}$. Full-length snaR was reverse transcribed into cDNA using the aforementioned method. snaR was amplified and inserted into a pcDNA3.1 vector (Sangon Biotech Co., Ltd., Shanghai, China) to make an snaR expression vector. The vectors were transfected into cells at a dose of $50 \mathrm{nM}$ using Lipofectamine 2000 (Invitrogen; Thermo Fisher Scientific, Inc.). Expression of snaR was detected by RT-qPCR. Subsequent experiments were performed $24 \mathrm{~h}$ after transfection only in cases where snaR overexpression was increased $>200 \%$ compared with the control untransfected cells and mock-transfected negative control cells (cells transfected with empty vector). For treatment with exogenous TGF- $\beta 1$ (Sigma-Aldrich; Merck KGaA, Darmstadt, Germany) and TGF- $\beta$ inhibitor SD 208 (R\&D Systems China Co., Ltd., Shanghai, China), cells $\left(10^{5}\right.$ cells $\left./ \mathrm{ml}\right)$ were treated for $24 \mathrm{~h}$ at $37^{\circ} \mathrm{C}$ prior to use. TGF- $\beta 1$ was used at concentrations of 10 and $30 \mathrm{ng} / \mathrm{ml}$ and TGF- $\beta$ inhibitor was used at a dose of $10 \mathrm{ng} / \mathrm{ml}$, based on the manufacturers' protocols.
ELISA. Plasma TGF- $\beta 1$ was detected using a human TGF- $\beta 1$ Quantikine ELISA kit (cat. no. DB100B; R\&D Systems China Co., Ltd.) according to the manufacturer's protocol.

Transwell migration and Matrigel invasion assays. Cells were collected and cell suspensions with a cell density of $4 \times 10^{4}$ cells $/ \mathrm{ml}$ were prepared using RPMI-1640 medium containing $1 \%$ FBS. From this cell suspension, $0.1 \mathrm{ml}$ was added into the upper chamber, and the lower chamber was filled with RPMI-1640 medium containing 20\% FBS. Cells were cultured for $12 \mathrm{~h}$ and the membranes were collected, cleaned using a cotton swab and stained with $0.5 \%$ crystal violet (Sigma-Aldrich; Merck $\mathrm{KGaA}$ ) for $15 \mathrm{~min}$ at room temperature. Invasion assays were performed according to the same method with the exception that the upper chamber was coated with Matrigel (EMD Millipore, Billerica, MA, USA) prior to the addition of the cells. A light microscope was used to count stained cells.

Western blotting. Cell lysis buffer (Beyotime Institute of Biotechnology, Haimen, China) was used to extract the total protein from the cells. A bicinchoninic acid assay was used to determine the protein concentration. Following denaturing at $95^{\circ} \mathrm{C}$ for $12 \mathrm{~min}$, protein samples were loaded $(30 \mu \mathrm{g}$ per well) on a $10 \%$ SDS-PAGE gel for separation and transferred to a polyvinylidene fluoride membrane. Membranes were blocked in 5\% skimmed milk for $1 \mathrm{~h}$ at room temperature. The primary antibodies used were rabbit anti-human primary antibodies against TGF- $\beta 1$ (1:1,500; cat. no. ab92486) and GAPDH (1:1,500; cat. no. ab37168; both Abcam, Cambridge, MA, USA) overnight at $4^{\circ} \mathrm{C}$. The secondary antibody used was goat anti-rabbit immunoglobulin-G conjugated with horseradish peroxidase (1:1,000; cat. no. MBS435036; MyBioSource, Inc., San Diego, CA, USA) at room temperature for $1 \mathrm{~h}$. Signal development was performed using enhanced chemiluminescence reagent (Sigma-Aldrich; Merck KGaA). ImageJ v1.6 (National Institutes of Health, Bethesda, MD, USA) was used for densitometric analysis.

Statistical analysis. GraphPad Prism 6 (GraphPad Software, Inc., La Jolla, CA, USA) was used for all the data analysis. Data from 3 biological replicates are presented as the mean \pm standard deviation. A Student's t-test was used to compare between two groups or a one-way analysis of variance followed by a post hoc Fisher's least significant difference test for comparisons between multiple groups. Correlations between plasma levels of snaR and TGF- $\beta 1$ were analyzed using Pearson's correlation coefficient. Associations between the clinicopathological data of patients and expression levels of snaR were analyzed using a $\chi^{2}$-test. $\mathrm{P}<0.05$ was considered to indicate a statistically significant difference.

\section{Results}

Expression levels of snaR and TGF- $\beta 1$ are significantly increased in patients with HCC compared with healthy controls. The expression level of snaR in liver biopsies and plasma was measured by RT-qPCR. ELISA was used to detect the plasma expression levels of TGF- $\beta 1$. The expression levels of snaR in liver biopsies (Fig. 1A) and plasma (Fig. 1B) were 

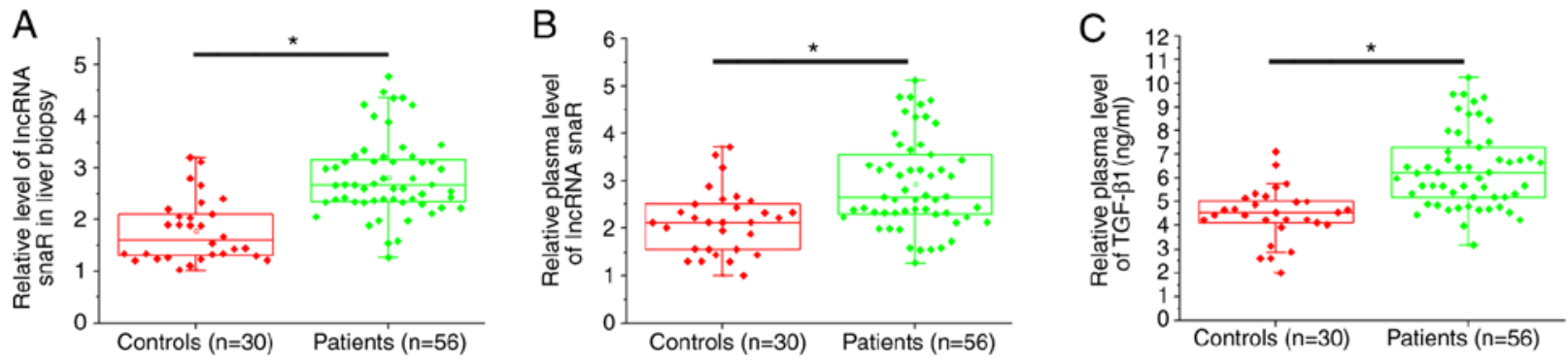

Figure 1. Expression levels of snaR and TGF- $\beta 1$ are significantly increased in patients with HCC compared with healthy controls. Expression levels of snaR in (A) liver biopsies and (B) plasma were significantly increased in patients with HCC compared with healthy controls. (C) In addition, serum expression levels of TGF- $\beta 1$ were significantly increased in patients with HCC compared with healthy controls. "P<0.05. snaR, small NF90-associated RNA; TGF- $\beta 1$, transforming growth factor- $\beta 1$; HCC, hepatocellular carcinoma; lncRNA, long non-coding RNA.
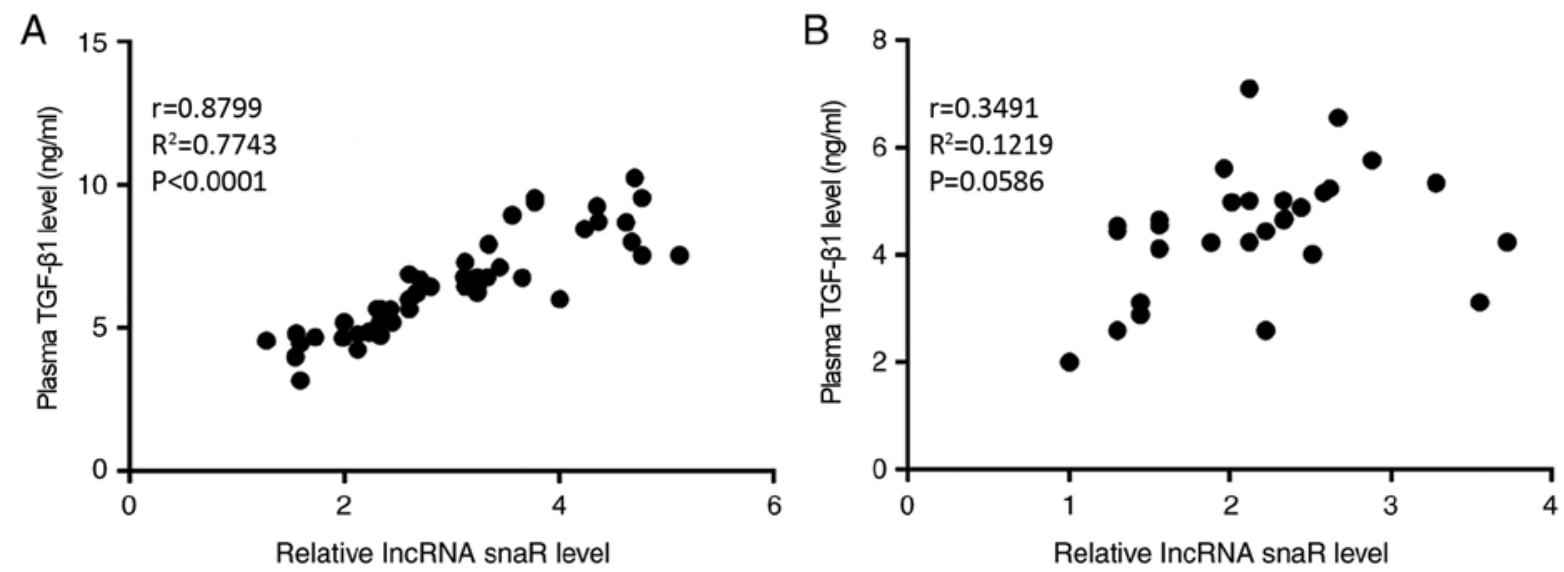

Figure 2. Plasma expression levels of snaR and TGF- $\beta 1$ are positively correlated in patients with HCC; however, not in healthy controls. Pearson's correlation coefficient analysis demonstrated that plasma expression levels of snaR and TGF- $\beta 1$ were positively correlated in (A) patients with HCC; however, not in (B) healthy controls. snaR, small NF90-associated RNA; TGF- $\beta 1$, transforming growth factor- $\beta 1$; HCC, hepatocellular carcinoma; lncRNA, long non-coding RNA; r, correlation coefficient; $\mathrm{R}^{2}$, coefficient of determination.

significantly increased in patients with HCC compared with the healthy controls $(\mathrm{P}<0.05)$. Additionally, the serum expression levels of TGF- $\beta 1$ were significantly increased in patients with HCC compared with the healthy controls $(\mathrm{P}<0.05)$.

Plasma expression levels of snaR and TGF- $\beta 1$ are positively correlated in patients with HCC. Correlations between the plasma expression levels of snaR and TGF- $\beta 1$ were analyzed using Pearson's correlation coefficient. A significantly positive correlation was identified between the plasma expression levels of snaR and TGF- $\beta 1$ in the patients with HCC (Fig. 2A; $\mathrm{P}<0.05)$. In contrast, there was no correlation between the plasma expression levels of snaR and TGF- $\beta 1$ in the healthy controls (Fig. 2B; P>0.05).

snaR expression is significantly associated with tumor metastasis; however, not with primary tumor diameter. Patients were divided into high $(\mathrm{n}=28)$ and low $(\mathrm{n}=28)$ snaR expression groups, according to the median expression levels of snaR in the liver biopsies (median, 2.87) and plasma (median, 2.72). Associations between the clinicopathological data of patients and expression levels of snaR were analyzed using a $\chi^{2}$-test. The results demonstrated that the expression levels of snaR in liver biopsies (Table I) and plasma (Table II) were significantly associated with the existence of tumor metastasis $(\mathrm{P}<0.05)$; however, were not associated with the primary tumor diameter, age, sex or smoking and drinking habits.

snaR is an upstream activator of TGF- $\beta 1$ in patients with $H C C$. To further investigate the correlation between snaR and TGF- $\beta 1$, snaR was overexpressed in cancer cells and the effects on TGF- $\beta 1$ expression were examined by western blotting. Overexpression of snaR following transfection was demonstrated in two cell lines, HEP G2 and C33A (Fig. 3A; $\mathrm{P}<0.05)$. Compared with the control cells and negative control cells, cells with snaR overexpression demonstrated significantly upregulated TGF- $\beta 1$ expression (Fig. $3 \mathrm{~B}$; $\mathrm{P}<0.05$ ). In contrast, treatment with exogenous TGF- $\beta 1$ at concentrations of 10 and $30 \mathrm{ng} / \mathrm{ml}$ demonstrated no significant effects on snaR expression (Fig. 3C; P>0.05).

snaR overexpression promotes cell migration and invasion. The data in Tables I and II suggested the potential involvement of snaR in the regulation of HCC metastasis. To investigate this hypothesis, cell migration and invasion were detected by Transwell migration and Matrigel invasion assays, respectively, following snaR overexpression. Compared with the control cells and negative control cells, cells with snaR overexpression demonstrated significantly increased migration (Fig. 4A; $\mathrm{P}<0.05$ ) and invasion (Fig. 4B; 
Table I. Association between clinicopathological feature of patients and expression levels of small NF90-associated RNA in cancer tissue.

\begin{tabular}{|c|c|c|c|c|c|}
\hline Clinicopathological features & Cases & High-expression & Low-expression & $\chi^{2}$-value & P-value \\
\hline Age & & & & 0.64 & 0.42 \\
\hline$>50$ years & 29 & 13 & 16 & & \\
\hline$<50$ years & 27 & 15 & 12 & & \\
\hline Sex & & & & 0.29 & 0.59 \\
\hline Male & 32 & 15 & 17 & & \\
\hline Female & 24 & 13 & 11 & & \\
\hline Smoking & & & & 0.29 & 0.59 \\
\hline Yes & 26 & 14 & 12 & & \\
\hline No & 30 & 14 & 16 & & \\
\hline Drinking & & & & 0.07 & 0.79 \\
\hline Yes & 33 & 17 & 16 & & \\
\hline No & 23 & 11 & 12 & & \\
\hline Primary tumor diameter & & & & 1.20 & 0.27 \\
\hline$>5 \mathrm{~cm}$ & 34 & 19 & 15 & & \\
\hline$<5 \mathrm{~cm}$ & 22 & 9 & 13 & & \\
\hline Tumor distant metastasis & & & & 5.79 & 0.02 \\
\hline Yes & 29 & 19 & 10 & & \\
\hline No & 27 & 9 & 18 & & \\
\hline
\end{tabular}

Table II. Association between clinicopathological data of patients and expression levels of small NF90-associated RNA in plasma.

\begin{tabular}{|c|c|c|c|c|c|}
\hline Clinicopathological features & Cases & High-expression & Low-expression & $\chi^{2}$-value & P-value \\
\hline Age & & & & 0.07 & 0.59 \\
\hline$>50$ years & 29 & 14 & 15 & & \\
\hline$<50$ years & 27 & 14 & 13 & & \\
\hline Sex & & & & 1.17 & 0.28 \\
\hline Male & 32 & 14 & 18 & & \\
\hline Female & 24 & 14 & 10 & & \\
\hline Smoking & & & & 0.29 & 0.59 \\
\hline Yes & 26 & 12 & 14 & & \\
\hline No & 30 & 16 & 14 & & \\
\hline Drinking & & & & 0.07 & 0.59 \\
\hline Yes & 33 & 17 & 16 & & \\
\hline No & 23 & 11 & 12 & & \\
\hline Primary tumor diameter & & & & 0.30 & 0.58 \\
\hline$>5 \mathrm{~cm}$ & 34 & 18 & 16 & & \\
\hline$<5 \mathrm{~cm}$ & 22 & 10 & 12 & & \\
\hline Tumor distant metastasis & & & & 5.79 & 0.02 \\
\hline Yes & 29 & 19 & 10 & & \\
\hline No & 27 & 9 & 18 & & \\
\hline
\end{tabular}

$\mathrm{P}<0.05)$. However, treatment with TGF- $\beta$ inhibitor SD 208 (R\&D Systems China Co., Ltd.) at a dose of $10 \mathrm{ng} / \mathrm{ml}$ significantly attenuated the effects of IncRNA snaR overexpression on cell migration (Fig. 4A; $\mathrm{P}<0.05$ ) and invasion (Fig. 4B; $\mathrm{P}<0.05)$.

\section{Discussion}

The present study is the first study investigating the involvement of snaR in human HCC, to the best of the author's knowledge. snaR may be involved in the regulation of tumor 

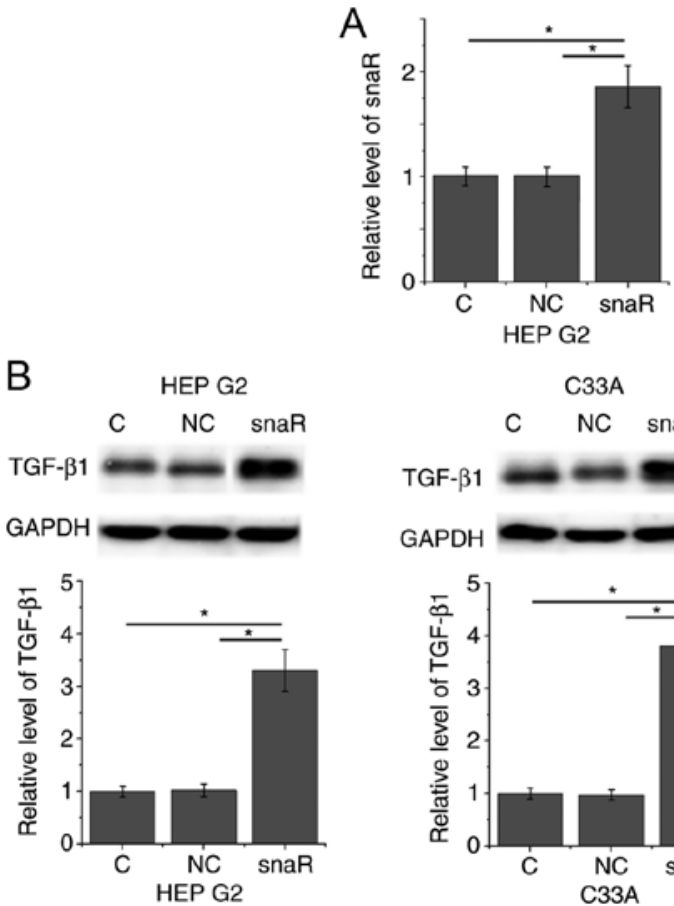

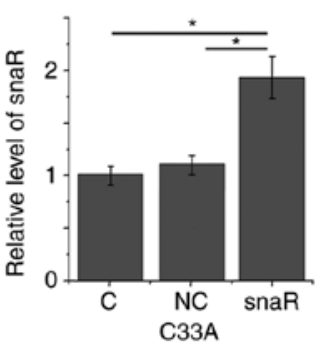

C
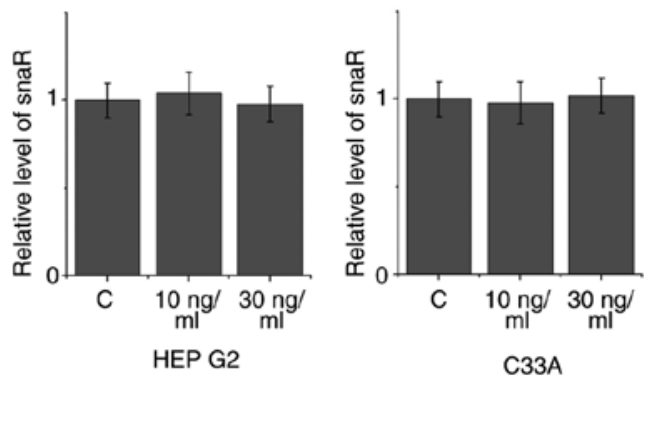

Figure 3. Long non-coding RNA snaR may be an upstream activator of TGF- $\beta 1$ in patients with hepatocellular carcinoma. (A) Overexpression of snaR in two cell lines following transfection with a snaR expression vector. (B) Overexpression of snaR led to significantly upregulated TGF- $\beta 1$ expression in two cell lines. (C) In contrast, treatment with exogenous TGF- $\beta 1$ at concentrations of 10 and $30 \mathrm{ng} / \mathrm{ml}$ demonstrated no significant effects on snaR expression. ${ }^{*} \mathrm{P}<0.05$. snaR, small NF90-associated RNA; TGF- $\beta 1$, transforming growth factor- $\beta 1$; , control; NC, negative control.

A
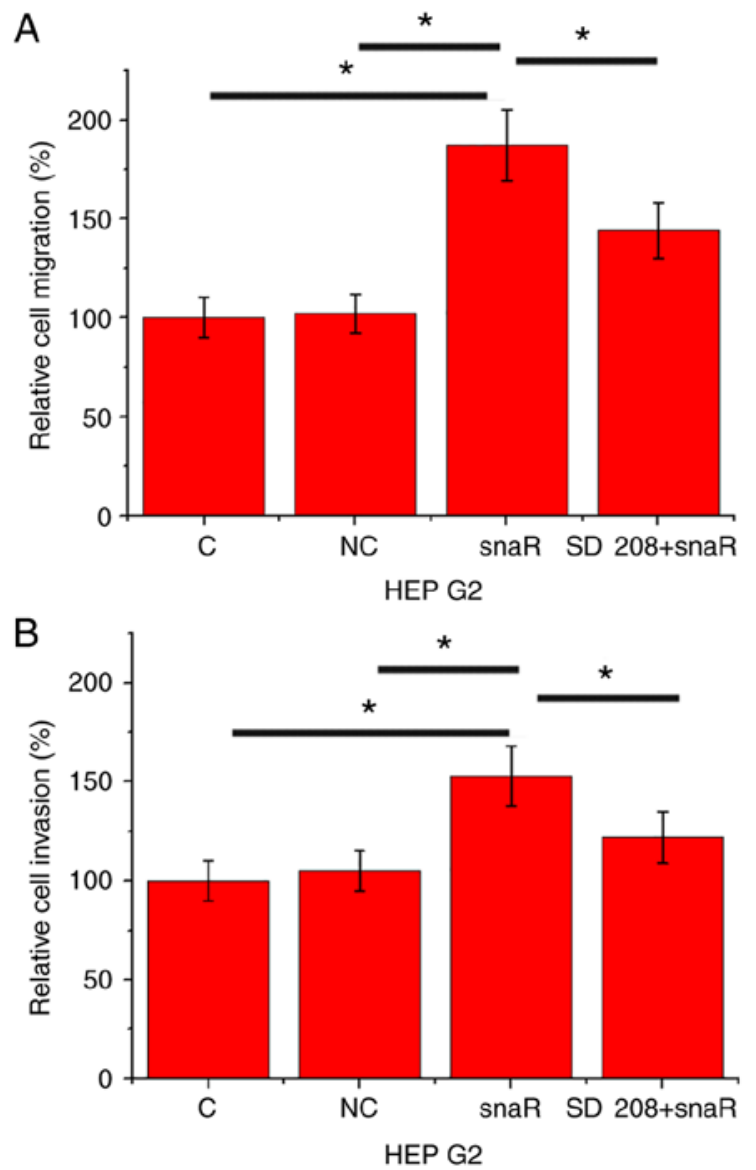

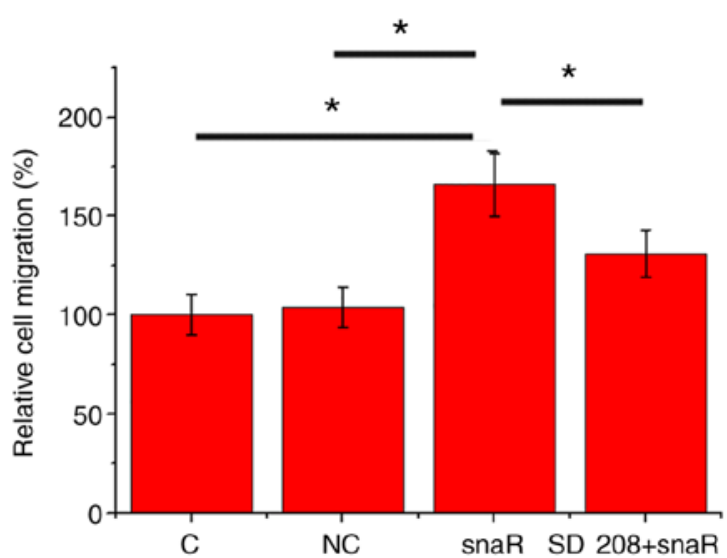

C

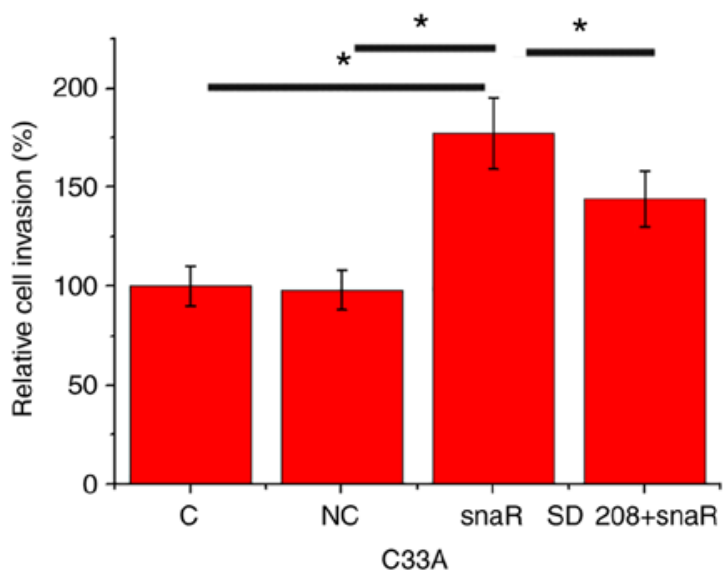

Figure 4. IncRNA snaR overexpression promotes hepatocellular carcinoma cell migration and invasion. Overexpression of snaR led to significantly increased cancer cell (A) migration and (B) invasion. However, treatment with transforming growth factor- $\beta 1$ inhibitor SD 208 at a dose of 10 ng/ml significantly attenuated the effects of lncRNA snaR overexpression on cell migration and invasion. ${ }^{*}<0.05$. IncRNA, long non-coding RNA; snaR, small NF90-associated RNA; C, control; NC, negative control. 
metastasis and the snaR mediated increase in HCC metastasis may be achieved through TGF- $\beta$ signaling.

Human hepatitis B virus (HBV) and/or hepatitis C virus (HCV) infection is the principal cause of HCC (15). The present study did not analyze the association between IncRNA snaR expression and HBV/HCV infection as 53 of the 56 patients in the present study were infected by $\mathrm{HBV} / \mathrm{HCV}$ and $\mathrm{HBV} / \mathrm{HCV}$-negative patients are rare. However, altered expression of snaR in the plasma of $\mathrm{HBV} / \mathrm{HCV}$-positive patients without HCC was not observed (data not shown). Therefore, the upregulation of snaR in patients with HCC is likely a by-product of HCC rather than a by-product of $\mathrm{HBV} / \mathrm{HCV}$ infection specifically.

TGF- $\beta 1$ serves as a tumor suppressor or pro-metastatic factor depending on the stage of cancer (16). The activation of TGF- $\beta 1$ signaling inhibits tumor cell growth at the very early stage of tumor development (17). However, TGF- $\beta 1$ signaling additionally promotes tumor cell metastasis during the later stages (18). In the present study, a significantly increased plasma expression level of TGF- $\beta 1$ in patients with HCC, compared with healthy controls, was observed. However, one limitation of the present study is that the majority of the patients included in the present study were in relatively advanced stages and thus, it remains unclear whether snaR expression is associated with the progression of cancer.

Although the functionality of a considerable number of IncRNAs has been characterized in HCC (19-21), those lncRNAs are either induced by $\mathrm{HBV} / \mathrm{HCV}$ infection or are involved in the whole process of cancer development, including tumor growth and metastasis (19-21). lncRNAs that are specifically involved in the metastasis of HCC are rare. In the present study, a significant association between plasma expression levels of snaR and the existence of tumor metastases in patients with HCC was observed. However, no significant association between plasma expression levels of snaR and tumor size was observed, suggesting a potential involvement of snaR in tumor metastasis. The cell migration and invasion assays demonstrated that upregulation of snaR promoted the migration and invasion of cells.

TGF- $\beta 1$ signaling interacts with different lncRNAs in different pathological processes $(9,10)$. In the present study, a positive correlation between plasma TGF- $\beta 1$ and snaR expression levels in patients with HCC was observed. Furthermore, snaR may be an upstream activator of TGF- $\beta 1$ signaling. This conclusion is based on the following observations: i) snaR overexpression led to increased expression of TGF- $\beta 1$ in cells; ii) treatment with exogenous TGF- $\beta 1$ did not alter snaR expression in cells; and iii) treatment with a TGF- $\beta 1$ inhibitor attenuated the enhancing effect of snaR overexpression on cancer cell migration and invasion. However, there may be disease-associated factors, which affect TGF- $\beta 1$ and snaR expression, as there was no correlation between plasma snaR and TGF- $\beta 1$ in the healthy controls. Another possibility is that the low expression levels of plasma snaR and TGF- $\beta 1$ in the healthy controls may make a correlation between these two factors more difficult to determine.

Due to limited resources, it was not possible to detect the expression of TGF- $\beta 1$ mRNA. Another limitation of the present study is that the majority of the patients were in relatively advanced stages and the number of patients at early stages was small. Therefore, it remains to be determined if there is an association between the disease stage and expression levels of TGF- $\beta 1$. In conclusion, lncRNA snaR was upregulated in patients with HCC and it may promote the metastasis of HCC through the upregulation of TGF- $\beta 1$. Therefore, IncRNA snaR is a potential therapeutic target for HCC.

\section{Acknowledgements}

Not applicable.

\section{Funding}

The present study was supported by The National Natural Science Foundation of China (grant no. 81660399).

\section{Availability of data and materials}

The datasets used and analyzed during the present study are available from the corresponding author on reasonable request.

\section{Authors' contributions}

ZS and LW designed experiments. ZS, DW, HW, JG and XL performed experiments. ZG, RZ, SX, TW, RM and RA analyzed data. LW drafted the manuscript. All authors approved the manuscript.

\section{Ethics approval and consent to participate}

Approval was obtained from the Ethics Committee of The Second Affiliated Hospital of Kunming Medical University and all patients signed informed consent.

\section{Patient consent for publication}

All patients provided consent for publication of the present study.

\section{Competing interests}

The authors declare that they have no competing interests.

\section{References}

1. Chang SS, Bochner BH, Chou R, Dreicer R, Kamat AM, Lerner SP, Lotan Y, Meeks JJ, Michalski JM, Morgan TM, et al: Treatment of non-metastatic muscle-invasive bladder cancer: AUA/ASCO/ASTRO/SUO guideline. J Urol 198: 552-559, 2017.

2. Khan MS, Kirkwood AA, Tsigani T, Lowe H, Goldstein R, Hartley JA, Caplin ME and Meyer T: Early changes in circulating tumor cells are associated with response and survival following treatment of metastatic neuroendocrine neoplasms. Clin Cancer Res 22: 79-85, 2016.

3. White DL, Kanwal F, Jiao L and El Serag HB: Epidemiology of hepatocellular carcinoma. In: Hepatocellular Carcinoma Diagnosis and Treatment. Carr BI (ed). Springer, Cham, Switzerland, pp 3-24, 2016.

4. Kummar S and Shafi NQ: Metastatic hepatocellular carcinoma. Clin Oncol (R Coll Radiol) 15: 288-294, 2003.

5. Zhu RX, Seto WK, Lai CL and Yuen MF: Epidemiology of hepatocellular carcinoma in the Asia-Pacific region. Gut Liver 10: 332-339, 2016. 
6. Derynck R, Akhurst RJ and Balmain A: TGF-beta signaling in tumor suppression and cancer progression. Nat Genet 29: $117-129,2001$.

7. Katsuno Y, Lamouille S and Derynck R: TGF- $\beta$ signaling and epithelial-mesenchymal transition in cancer progression. Curr Opin Oncol 25: 76-84, 2013.

8. Wei W and Birrer MJ: Abstract 5401: TGF- $\beta$ signaling inhibition as a potential approach to target suboptimally debulked ovarian tumors. Cancer Res 75: 5401-5401, 2015.

9. Yuan J, Yang F, Wang F, Ma JZ, Guo YJ, Tao QF, Liu F, Pan W, Wang TT, Zhou CC, et al: A long noncoding RNA activated by TGF- $\beta$ promotes the invasion-metastasis cascade in hepatocellular carcinoma. Cancer Cell 25: 666-681, 2014

10. Li W and Kang Y: A new Lnc in metastasis: Long noncoding RNA mediates the prometastatic functions of TGF- $\beta$. Cance Cell 25: 557-559, 2014.

11. Mercer TR, Dinger ME and Mattick JS: Long non-coding RNAs: Insights into functions. Nat Rev Genet 10: 155-159, 2009.

12. Gutschner $T$ and Diederichs $S$ : The hallmarks of cancer: A long non-coding RNA point of view. RNA Biol 9: 703-719, 2012.

13. Lee H, Kim C, Ku JL, Kim W, Yoon SK, Kuh HJ, Lee JH, Nam SW and Lee EK: A long non-coding RNA snaR contributes to 5-fluorouracil resistance in human colon cancer cells. Mol Cells 37: 540-546, 2014.

14. Livak KJ and Schmittgen TD: Analysis of relative gene expression data using real-time quantitative PCR and the 2(-Delta Delta C(T)) method. Methods 25: 402-408, 2001.

15. El-Serag HB: Epidemiology of viral hepatitis and hepatocellular carcinoma. Gastroenterology 142: 1264-1273.e1, 2012.
16. Akhurst RJ and Derynck R: TGF-beta signaling in cancer-a double-edged sword. Trends Cell Biol 11: S44-S51, 2001.

17. Markowitz SD and Roberts AB: Tumor suppressor activity of the TGF-beta pathway in human cancers. Cytokine Growth Factor Rev 7: 93-102, 1996.

18. Pardali K and Moustakas A: Actions of TGF-beta as tumor suppressor and pro-metastatic factor in human cancer. Biochim Biophys Acta 1775: 21-62, 2007.

19. Huang JF, Guo YJ, Zhao CX, Yuan SX, Wang Y, Tang GN, Zhou WP and Sun SH: Hepatitis B virus X protein (HBx)-related long noncoding RNA (lncRNA) down-regulated expression by HBx (Dreh) inhibits hepatocellular carcinoma metastasis by targeting the intermediate filament protein vimentin. Hepatology 57: 1882-1892, 2013.

20. Yang X, Xie X, Xiao YF, Xie R, Hu CJ, Tang B, Li BS and Yang SM: The emergence of long non-coding RNAs in the tumorigenesis of hepatocellular carcinoma. Cancer Lett 360: 119-124, 2015

21. Chen Z, Yu C, Zhan L, Pan Y, Chen L and Sun C: LncRNA CRNDE promotes hepatic carcinoma cell proliferation, migration and invasion by suppressing miR-384. Am J Cancer Res 6: 2299-2309, 2016

This work is licensed under a Creative Commons Attribution-NonCommercial-NoDerivatives 4.0 International (CC BY-NC-ND 4.0) License. 